\title{
Effectiveness and Safety of Implant-Based Breast Reconstruction in Locally Advanced Breast Carcinoma: A Matched Case-Control Study
}

\author{
René Aloisio da Costa Vieira ${ }^{a}$ b Luciana Machado Ribeiro ${ }^{a-c}$ \\ Guilherme Freire Angotti Carrara $^{\text {b }}$ Lucas Faria Abrahão-Machado ${ }^{d}$ \\ Ligia Maria Kerr $^{d}$ Afonso Celso Pinto Nazárioc

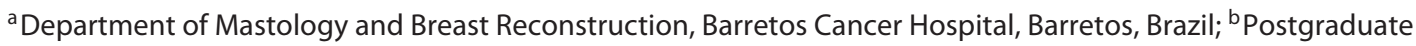

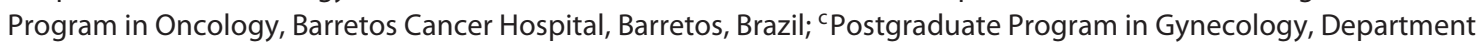 \\ of Gynecology, Discipline of Mastology, Federal University of São Paulo (UNIFESP), São Paulo, Brazil; d Department of \\ Pathology, Barretos Cancer Hospital, Barretos, Brazil
}

\section{Keywords}

Breast neoplasms · Mastectomy · Reconstructive surgical procedures · Prostheses and implants · Matched case-control study
IBBR, 14.6\% (7/48) of patients presented loss of prosthesis and $48.8 \%$ (20/41) developed capsular contracture. Conclusion: Immediate IBBR may be a safe and effective surgical procedure in selected patients with $L A B C$.

(C) 2019 S. Karger AG, Basel

\section{Introduction}

Locally advanced breast carcinoma (LABC) is characterized by tumours larger than $5 \mathrm{~cm}$; the presence of a mass or fixed axillary lymph nodes; the involvement of supraclavicular, infraclavicular or ipsilateral internal mammary chain lymph nodes; skin ulceration, erythema, ipsilateral satellite or "peau d'orange" nodules; fixation of the tumour in the chest wall; or inflammatory carcinoma [1]. Neoadjuvant chemotherapy (NCT) and adjuvant radiation therapy are indicated for the majority of patients with non-metastatic LABC, where the most frequent surgery performed is radical mastectomy.

Mastectomy with skin preservation has been shown to be a safe and effective procedure with acceptable local recurrence rates [2-5], but in most series, this procedure is rarely performed in patients with $\mathrm{LABC}$ where the type

René Aloisio da Costa Vieira is an active member of the EORTC Quality of Life Group.

\section{KARGER}

(C) 2019 S. Karger AG, Basel 
and timing of reconstruction is a matter of debate [6-8]. These patients are considered difficult candidates for immediate implant-based breast reconstruction (IBBR) [6, 7] due to a significantly higher risk of local recurrence, more aggressive adjuvant treatments and reduced survival.

LABC has been considered a relative contraindication for IBBR. However, a growing number of studies suggest that IBBR is a safe and acceptable option [9-14]. Skinsparing mastectomy (SSM) or nipple-sparing mastectomy (NSM) are surgical procedures [15] that can be performed to facilitate IBBR $[9,16]$ but may increase the morbidity of mastectomy, with skin necrosis rates of up to $16.7 \%[9,14,17]$. Radiation therapy is typically indicated for these patients to increase locoregional control, which contributes to capsular contracture, pain, infection and fibrosis of the skin, which cause asymmetry of the breasts and undesirable cosmetic results $[14,18,19]$.

Studies that compare IBBR with conventional mastectomy $(\mathrm{CM})$ have shown similar results $[9,17,20]$, but studies evaluating IBBR in LABC are scarce, and the majority are limited to small groups of patients with controversial outcomes $[9,11,12,21-25]$. Nonetheless, IBBR is still performed in a small number of cases with LABC [14, 26]; and few authors performed this procedure exclusively $[27,28]$, as reconstruction is commonly performed in patients with a better tumour stage or in patients with a better therapeutic response.

The present study constitutes a case-control study to exclusively match patients with LABC who are undergoing NCT with the objective of evaluating the safety of IBBR in these patients.

\section{Materials and Methods}

The Ethics and Research Committee approved this retrospective study under protocol numbers 135/2008 and 1308/2016. The study evaluated patients with non-metastatic LABC undergoing mastectomy. The patients were treated from October 2005 to December 2011 and were followed up at a minimum until December 2016.

During this period, 323 patients underwent CM, and 48 underwent immediate IBBR. From this total, a matched case-control selection was performed based on the clinical and prognostic characteristics. As this was a matched study, the authors randomly performed the selection of the control groups with the objective that the groups had similar characteristics before and after NCT. We prepared the time line and began the case selection. Initially, IBBR and CM were compared, but the groups had different characteristics before NCT. Seven simulations were performed using the proportions 1:4,1:3 and 1:2. The selection was sequential based on the time of treatment (nested), and we paired the controls based on the time of the beginning of treatment, considering a period of about 6 months. It was not possible to have similar group characteristics before and after NCT, so we opted to compare the control groups before and after NCT. One of the four 1:2 groups was chosen. We chose the groups that showed more similar characteristics before
NCT. In the first model, patients were matched based on the prognostic characteristics prior to NCT, which included tumour size, clinical stage (CS)-TNM, T-TNM and N-TNM and molecular subtype. TNM 7th edition was used for clinical staging. In the second model, patients were matched initially according to response to NCT and later according to CS.

The proposed chemotherapy regimen was $4 \mathrm{AC} / 4 \mathrm{~T}$ ( 4 cycles of doxorubicin $60 \mathrm{mg} / \mathrm{m}^{2}+$ cyclophosphamide $600 \mathrm{mg} / \mathrm{m}^{2}$ i.v., followed by 4 cycles of paclitaxel $175 \mathrm{mg} / \mathrm{m}^{2}$ i.v.) or $4 \mathrm{AC} / 12 \mathrm{~T}$ ( 4 cycles of doxorubicin $60 \mathrm{mg} / \mathrm{m}^{2}+$ cyclophosphamide $600 \mathrm{mg} / \mathrm{m}^{2}$ i.v., followed by 12 cycles of paclitaxel $80 \mathrm{mg} / \mathrm{m}^{2}$ i.v.).

The clinical and pre-treatment pathological characteristics, the type of treatment performed, the response after NCT, recurrence, recurrence-free interval, overall survival and disease-free survival were evaluated. Local, locoregional and distant recurrence were also assessed. All pathological data were reviewed by 2 pathologists (L.F.A.-M. and L.M.K.). A molecular classification was performed [29]. For the assessment of disease-free survival, the date of surgery and the last follow-up date or the date of death were considered. For the evaluation of the pathological response to NCT, we considered NSABP criteria, the response according to the RECISTBreast criteria [30] and the model proposed at M.D. Anderson cancer centre [31]. The main outcomes related to the prosthesis were also assessed, that is, loss of the prosthesis, capsular contracture [32] and the need for prosthesis replacement. In cases of postoperative loss of the breast prosthesis, the patient was kept in the prosthesis group.

The $\chi^{2}$ test was used to compare the categorical variables, and Fisher's test was used if values were $\leq 5$. The Mann-Whitney test was used to compare continuous variables. For the analysis of recurrence and survival, the Kaplan-Meier method was used, while the log-rank method was used to compare the curves. Kaplan-Meier and hazard risk curves were reported. The IBM SPSS ${ }^{\circledR} 20$ for $\mathrm{Mac}^{\circledR}$ was used for analysis.

\section{Results}

In all, 48 patients underwent immediate IBBR, 148 patients were used as controls, 52 patients were matched exclusively using model 1, 52 patients were matched using model 2 and 44 patients were matched using both models. Because of the criteria used for the groups' selection, 127 patients were excluded.

The mean age of the patients who underwent IBBR (cases) was 43 years (95\% CI 40.7-45.2), and the mean tumour size was $5.8 \mathrm{~cm}$ (95\% CI 5.9-6.2). In all, 83.3\% of the tumours were stage T3-T4, 91.7\% exhibited lymph node metastasis and $85.4 \%$ were in CS III. Histologically, $79.2 \%$ were ductal carcinomas, and $85.5 \%$ were histological grade 2 or 3 . Regarding the molecular subtype, $35.4 \%$ of patients had luminal HER2-negative tumours, 39.6\% had luminal HER2-positive tumours, $14.6 \%$ had HER2positive tumours, and $10.4 \%$ had triple-negative tumours. The initial proposed chemotherapy scheme was based on the AC-T regimen, which was changed in $14.6 \%$ of the patients mainly due to disease progression. 
Table 1. Comparison $\left(\chi^{2}\right)$ of the clinical-pathological characteristics between the groups

\begin{tabular}{|c|c|c|c|c|c|c|c|}
\hline & \multirow[t]{2}{*}{ Cases } & \multicolumn{3}{|l|}{ Model 1} & \multicolumn{3}{|l|}{ Model 2} \\
\hline & & control 1 & total & $p$ & control 2 & total & $p$ \\
\hline \multicolumn{8}{|l|}{ Before treatment } \\
\hline \multicolumn{8}{|l|}{ T-TNM } \\
\hline $\mathrm{T} 1+\mathrm{T} 2$ & $68(16.7)$ & $10(10.4)$ & 18 & \multirow[t]{3}{*}{0.41} & $10(10.4)$ & 18 & \multirow[t]{3}{*}{0.52} \\
\hline T3 & $28(58.3)$ & $56(58.3)$ & 84 & & $57(59.4)$ & 85 & \\
\hline $\mathrm{T} 4$ & $12(25.0)$ & $30(31.3)$ & 42 & & $29(30.2)$ & 41 & \\
\hline \multicolumn{8}{|l|}{ N-TNM } \\
\hline No & $4(8.3)$ & $9(9.4)$ & 13 & \multirow[t]{3}{*}{0.95} & $9(9.4)$ & 13 & \multirow[t]{3}{*}{0.61} \\
\hline N1 & $32(66.7)$ & $65(67.7)$ & 97 & & $56(58.3)$ & 88 & \\
\hline $\mathrm{N} 2+\mathrm{N} 3$ & $12(25.0)$ & $22(22.9)$ & 34 & & $31(32.3)$ & 43 & \\
\hline \multicolumn{8}{|l|}{ CS } \\
\hline IIB & $7(14.6)$ & $7(7.3)$ & 14 & \multirow[t]{3}{*}{0.31} & $8(8.3)$ & 15 & \multirow[t]{3}{*}{0.47} \\
\hline IIIA & $29(60.4)$ & $58(60.4)$ & 87 & & $59(61.5)$ & 88 & \\
\hline IIIB + IIIC & $12(25.0)$ & $31(32.3)$ & 43 & & $29(30.2)$ & 41 & \\
\hline \multicolumn{8}{|l|}{$\mathrm{CS}$} \\
\hline II & $7(14.6)$ & $7(7.3)$ & 14 & \multirow[t]{2}{*}{0.16} & $8(8.3)$ & 15 & \multirow[t]{2}{*}{0.26} \\
\hline III & $41(85.4)$ & $89(92.7)$ & 130 & & $88(91.7)$ & 129 & \\
\hline \multicolumn{8}{|l|}{ Molecular subtype } \\
\hline Luminal HER-negative & $17(35.4)$ & $44(45.8)$ & 61 & \multirow[t]{4}{*}{0.16} & $52(54.2)$ & 69 & \multirow[t]{4}{*}{0.01} \\
\hline Luminal HER-positive & $19(39.6)$ & $2324.0)$ & 42 & & $14(14.6)$ & 33 & \\
\hline HER2-positive & $7(14.6)$ & $11(11.5)$ & 18 & & $16(16.7)$ & 23 & \\
\hline Triple-negative & $5(10.4)$ & $18(18.7)$ & 23 & & $14(14.6)$ & 33 & \\
\hline \multicolumn{8}{|l|}{ Histological type } \\
\hline IDC & $38(79.2)$ & $78(81.3)$ & 116 & 0.92 & $77(80.2)$ & 115 & 0.98 \\
\hline LIC & $5(10.4)$ & $10(10.4)$ & 15 & & $9(9.4)$ & 14 & \\
\hline Others & $5(10.4)$ & $8(9.4)$ & 13 & & $10(10.4)$ & 15 & \\
\hline Histological grade & & & & & & & \\
\hline Grade 1 & $7(14.6)$ & $10(10.4)$ & 17 & 0.77 & $7(50.0)$ & 14 & 0.38 \\
\hline Grade 2 & $21(43.8)$ & $45(46.9)$ & 66 & & $43(45.3)$ & 64 & \\
\hline Grade 3 & $20(41.7)$ & $39(40.6)$ & 59 & & $45(47.4)$ & 65 & \\
\hline Nuclear grade & & & & & & & \\
\hline Grade 1 & $6(12.5)$ & $9(9.4)$ & 15 & 0.39 & $10(10.4)$ & 16 & 0.92 \\
\hline Grade 2 & $14(29.2)$ & $39(40.6)$ & 53 & & $30(31.2)$ & 44 & \\
\hline Grade 3 & $28(58.3)$ & $48(50.0)$ & 76 & & $56(58.3)$ & 84 & \\
\hline NCT response & & & & & & & \\
\hline MDA & & & & & & & \\
\hline Disease progression & $3(6.2)$ & $15(15.6)$ & 18 & 0.03 & $8(8.3)$ & 11 & 0.58 \\
\hline Stable disease & $7(14.6)$ & $7(7.3)$ & 14 & & $10(10.4)$ & 17 & \\
\hline Solid mass & $1327.1)$ & $44(45.8)$ & 57 & & $38(39.6)$ & 51 & \\
\hline Multifocal residual disease & $13(27.1)$ & $18(18.7)$ & 31 & & $22(22.9)$ & 35 & \\
\hline No residual disease & $12(25.0)$ & $12(12.5)$ & 24 & & $18(18.8)$ & 30 & \\
\hline RECIST-B & & & & & & & \\
\hline Complete response & $15(31.2)$ & $14(14.6)$ & 29 & 0.08 & $25(26.0)$ & 40 & 0.93 \\
\hline Partial response & $20(41.7)$ & $50(52.1)$ & 70 & & $43(44.8)$ & 63 & \\
\hline Stable disease & $10(20.8)$ & $19(19.8)$ & 29 & & $22(22.9)$ & 32 & \\
\hline Disease progression & $3(6.2)$ & $13(13.5)$ & 16 & & $6(3.2)$ & 9 & \\
\hline NSABP & & & & & & & \\
\hline Absent & $35(72.9)$ & $84(87.5)$ & 119 & 0.03 & $74(77.1)$ & 109 & 0.68 \\
\hline Present & $13(27.1)$ & $12(12.5)$ & 25 & & $22(22.9)$ & 35 & \\
\hline
\end{tabular}

T, tumour (in the TNM classification); N, lymph node (in the TNM classification); CS, clinical stage; IDC, invasive ductal carcinoma; LIC, invasive lobular carcinoma; NCT, neoadjuvant chemotherapy; MDA, M.D. Anderson classification; RECIST-B, Response Evaluation Criteria in Solid Tumours-Breast; NSABP, National Surgical Adjuvant Breast and Bowel Project. 
Table 2. Comparison ${ }^{\mathrm{a}}$ of continuous variables

\begin{tabular}{lccccc}
\hline & Mean \pm SD & Min.-Max. & Median & $95 \%$ CI & $p$ \\
\hline Age, years & & & & & \\
$\quad$ Case & $43.0 \pm 8.0$ & $21.5-62.0$ & 44.5 & $40.7-45.4$ & - \\
$\quad$ Control 1 & $49.3 \pm 10.6$ & $29.6-72.6$ & 47.9 & $47.1-51.4$ & 0.001 \\
$\quad$ Control 2 & $49.0 \pm 10.7$ & $26.5-72.3$ & 49.2 & $46.8-51.2$ & 0.001 \\
Tumour size, cm & & & & \\
$\quad$ Case & $5.8 \pm 1.2$ & $3.0-10.0$ & 6.0 & $5.4-6.2$ & - \\
$\quad$ Control 1 & $6.2 \pm 1.4$ & $2.5-11.0$ & 6.0 & $5.9-6.5$ & 0.001 \\
$\quad$ Control 2 & $6.8 \pm 1.9$ & $2.0-14.0$ & 7.0 & $6.4-7.2$ & 0.001 \\
Follow-up time, months & & & & \\
$\quad$ Case & $74.7 \pm 26.2$ & $12.9-123.6$ & 75.9 & $67.1-82.4$ & - \\
$\quad$ Control 1 & $67.9 \pm 31.2$ & $10.6-127.8$ & 67.9 & $61.6-74.2$ & 0.05 \\
$\quad$ Control 2 & $64.7 \pm 29.4$ & $12.8-122.5$ & 67.2 & $58.8-70.7$ & 0.05 \\
\hline \multicolumn{2}{l}{ SD, standard deviation; Min., minimum; Max., maximum; CI, confidence interval. ${ }^{\text {a }}$ Mann-Whitney test. } \\
\hline
\end{tabular}

\section{Case Group}

Of the patients who underwent immediate IBBR, 45 received permanent breast prosthesis, 2 were subjected to latissimus dorsi muscle flap transfer and permanent breast prosthesis and 1 received a temporary breast expander with subsequent replacement by a permanent prosthesis. Twelve patients had T4-TNM tumours, all of which were clinically selected and only 1 was confirmed by biopsy. Of these, 6 presented pathologic complete response (pCR), 4 presented partial response, and 2 presented stable disease. SSM and NSM were performed in $87.5 \%(n=42)$ and $12.5 \%(n=6)$ of the patients, respectively. Axillary lymphadenectomy was performed in 91.6\% ( $n=44)$ of patients. In this group, the pCR-NSABP rate was $27.1 \%(n=13)$. The majority of the HER2-positive patients received adjuvant trastuzumab. Only 1 patient did not receive adjuvant radiation therapy, whereas the majority received radiation therapy in the chest wall and supraclavicular fossa. At a mean follow-up of 74.7 months, $6.2 \%(n=3)$ presented with local recurrence, while $8.3 \%(n=4)$ presented with locoregional recurrence. None of the T4-TNM patients had local recurrence. Bone metastasis was the most frequent (17.8\%), followed by liver (15.2\%) and lung (10.9\%) metastasis. As of the last evaluation date, $18.8 \%(n=9)$ had died due to cancer, $6.3 \%(n=3)$ were alive with recurrence, and $75.0 \%$ were alive without disease. The overall and specific survival rate at 96 months was $81.1 \%$, the disease-free survival rate was $68.2 \%$, and the recurrence-free survival rate was $92.3 \%$.

It was observed that $14.6 \%(n=7)$ of the patients presented a loss of prosthesis due to skin necrosis, which occurred within the first 2 months after surgery. Regarding reconstruction, and excluding prosthesis loss, the most frequent late complication observed was capsular contracture, which occurred in $48.8 \%$ (20/41) of the patients.
Of the contractures observed, $4.9 \%(n=2)$ were Baker I, 24.4\% $(n=10)$ were Baker II, $12.2 \%(n=5)$ were Baker III, and 7.3\% $(n=3)$ were Baker IV. Nine patients underwent breast prosthesis replacement by capsulotomy (4 patients), latissimus dorsi muscle flap transfer (4 patients) and prosthesis shape correction (1 patient). Thirty-four patients underwent contralateral symmetrisation, of which 22 were synchronous (same-day) and 12 were metachronous (at a different time).

\section{Control Model 1}

In this model, the patients were matched at a 1:2 ratio according to tumour size, CS-TNM, T-TNM, N-TNM and molecular subtype. When the categorical variables were compared between the groups, the patients presented statistically similar characteristics with respect to CSTNM, T-TNM, N-TNM, histological type and histological and nuclear grade (Table 1).

Comparing continuous variables in model 1 with the IBBR group (Table 2), it was found that the control group patients were older $(p=0.001)$, had larger tumours at diagnosis $(p=0.001)$ even after the matching attempt and presented a lower follow-up time $(p=0.05)$, which was influenced by the lower overall and specific survival.

No difference was observed between the groups with regard to treatment, except the fact that the model 1 group (Table 1) was more frequently subjected to axillary lymphadenectomy $(p=0.04)$. Evaluating the response to NCT (Table 1), patients selected in the model 1 group presented a worse response to NCT $(p=0.03)$ and a lower pCR rate (12.5\% in controls vs. $27.1 \%$ in IBBR).

Although the local recurrence rate was higher in the model 1 group (15.6\%; OR 2.78), the rate was not significantly different between the groups (Table $3 ; p=0.18$ ), but bone recurrence $(p=0.05)$ and cancer-related death $(p=0.02)$ were higher in the model 1 group. Overall sur- 
Table 3. Comparison $\left(\chi^{2}\right)$ of the treatment performed between groups and follow-up results

\begin{tabular}{|c|c|c|c|c|c|c|c|}
\hline & \multirow[t]{2}{*}{ Cases } & \multicolumn{3}{|l|}{ Model 1} & \multicolumn{3}{|l|}{ Model 2} \\
\hline & & control 1 & total & $p$ & control 2 & total & $p$ \\
\hline \multicolumn{8}{|l|}{ Neoadjuvant treatment } \\
\hline \multicolumn{8}{|l|}{ Proposed NCT } \\
\hline $4 \mathrm{AC} / 4 \mathrm{~T}$ & $35(72.9)$ & $79(82.3)$ & 114 & 0.19 & $82(85.4)$ & 117 & 0.11 \\
\hline $4 \mathrm{AC} / 12 \mathrm{~T}$ & $13(27.1)$ & $17(17.7)$ & 30 & & $14(14.6)$ & 27 & \\
\hline \multicolumn{8}{|l|}{ Change in NCT regimen } \\
\hline No & $41(85.4)$ & $73(76.0)$ & 114 & 0.19 & $77(80.2)$ & 118 & 0.50 \\
\hline Yes & 7 (14.6) & $23(24.0)$ & 30 & & $19(19.8)$ & 26 & \\
\hline \multicolumn{8}{|l|}{ Final NCT regimen } \\
\hline $4 \mathrm{AC} / 4 \mathrm{~T}$ & $32(66.7)$ & $61(63.5)$ & 93 & 0.07 & $68(70.8)$ & 100 & 0.05 \\
\hline $4 \mathrm{AC} / 12 \mathrm{~T}$ & $11(22.9)$ & $12(12.5)$ & 23 & & $9(9.4)$ & 20 & \\
\hline Others & $5(10.4)$ & $23(24.0)$ & 28 & & $19(19.8)$ & 24 & \\
\hline \multicolumn{8}{|l|}{ Axillary surgery } \\
\hline No or SLN & $4(8.4)$ & $1(1.1)$ & 5 & 0.04 & $1(1.0)$ & 5 & 0.04 \\
\hline Lymphadenectomy & 44 (91.6) & $95(98.9)$ & 139 & & $95(99.0)$ & 139 & \\
\hline \multicolumn{8}{|l|}{ Adjuvant treatment } \\
\hline \multicolumn{8}{|l|}{ Radiation } \\
\hline Neoadjuvant & $1(2.1)$ & 0 & 1 & 0.30 & 0 & 1 & 0.36 \\
\hline Adjuvant & $46(95.8)$ & $92(95.8)$ & 138 & & $94(97.9)$ & 140 & \\
\hline Not performed & $1(2.1)$ & $4(4.2)$ & 5 & & $2(2.1)$ & 3 & \\
\hline \multicolumn{8}{|l|}{ Adjuvant radiation } \\
\hline Absent & $1(2.1)$ & $4(4.2)$ & 5 & 0.11 & $3(3.2)$ & 4 & 0.23 \\
\hline Chest wall & $17(35.4)$ & $25(26.0)$ & 42 & & $32(33.4)$ & 49 & \\
\hline Chest wall/SCF & $28(58.3)$ & $67(69.8)$ & 95 & & $61(63.5)$ & 93 & \\
\hline Origin & $2(4.2)$ & 0 & 2 & & 0 & 2 & \\
\hline \multicolumn{8}{|l|}{ Trastuzumab adjuvant $\mathrm{t}^{\mathrm{a}}$} \\
\hline No HER2 & $27(57.4)$ & $73(76.0)$ & 100 & 0.09 & $66(70.2)$ & 93 & 0.30 \\
\hline HER2+/received & $16(34.0)$ & $11(11.5)$ & 27 & & $19(20.2)$ & 35 & \\
\hline HER2+/did not receive & $4(8.5)$ & $11(11.5)$ & 15 & & $9(9.6)$ & 13 & \\
\hline \multicolumn{8}{|l|}{ Endocrine therapy adjuvant ${ }^{\mathrm{a}}$} \\
\hline Present & $32(77.7)$ & $61(67.8)$ & 93 & 0.89 & $63(66.3)$ & 95 & 0.97 \\
\hline Absent & $16(33.3)$ & $29(32.2)$ & 41 & & $32(33.7)$ & 48 & \\
\hline \multicolumn{8}{|l|}{ Follow-up } \\
\hline Type of first recurrence & & & & & & & \\
\hline Absent & $34(70.8)$ & $53(55.2)$ & 77 & 0.09 & $56(58.3)$ & 90 & 0.26 \\
\hline Local/LR & $2(4.2)$ & $9(9.4)$ & 11 & & $9(9.4)$ & 11 & \\
\hline Distant & $11(22.9)$ & $27(28.1)$ & 38 & & $23(24.0)$ & 34 & \\
\hline LR and distant & $1(2.1)$ & $7(7.3)$ & 8 & & $8(8.3)$ & 9 & \\
\hline Local recurrence & & & & & & & \\
\hline Absent & $45(93.8)$ & $81(84.4)$ & 126 & 0.18 & $82(86.3)$ & 127 & 0.26 \\
\hline Present & $3(6.2)$ & 15 (15.6) & 18 & & $13(13.7)$ & 16 & \\
\hline LR recurrence & & & & & & & \\
\hline Absent & 44 (91.7) & $79(82.3)$ & 123 & 0.21 & $76(80.0)$ & 120 & 0.09 \\
\hline Present & $4(8.3)$ & $17(17.7)$ & 21 & & $19(20.0)$ & 23 & \\
\hline Lung metastasis & & & & & & & \\
\hline Absent & $41(89.1)$ & $6874.7)$ & 109 & 0.07 & $65(69.9)$ & 106 & 0.01 \\
\hline Present & $5(10.9)$ & $23(25.3)$ & 28 & & $28(30.1)$ & 33 & \\
\hline Liver metastasis & & & & & & & \\
\hline 4.5 & $39(84.8)$ & $73(83.0)$ & 112 & 0.79 & $70(77.8)$ & 109 & 0.37 \\
\hline Present & $7(15.2)$ & $15(17.0)$ & 22 & & $20(22.2)$ & 27 & \\
\hline Bone metastasis & & & & & & & \\
\hline Absent & $37(82.2)$ & $60(65.9)$ & 97 & 0.05 & $65(70.7)$ & 102 & 0.21 \\
\hline Present & $8(17.8)$ & $31(34.1)$ & 39 & & $27(29.3)$ & 35 & \\
\hline Brain metastasis & & & & & & & \\
\hline Absent & $43(95.6)$ & 77 (88.5) & 120 & 0.22 & $81(89.0)$ & 124 & 0.34 \\
\hline Present & $2(4.4)$ & $10(11.5)$ & 12 & & $10(11.0)$ & 12 & \\
\hline Specific-cancer death & & & & & & & \\
\hline Alive & $39(81.2)$ & $59(61.5)$ & 98 & 0.02 & $58(60.4)$ & 97 & 0.01 \\
\hline Death & $9(18.8)$ & $37(38.5)$ & 46 & & 38 (39.6) & 47 & \\
\hline Overall death & & & & & & & \\
\hline 4.5 & $39(81.2)$ & $55(57.3)$ & 94 & 0.004 & $54(56.2)$ & 93 & 0.003 \\
\hline Death & $9(18.8)$ & $41(42.7)$ & 50 & & $42(43.8)$ & 51 & \\
\hline
\end{tabular}

NCT, neoadjuvant chemotherapy; SLN, sentinel lymph node; SCF, supraclavicular fossa; LR, locoregional. a Missing value. 


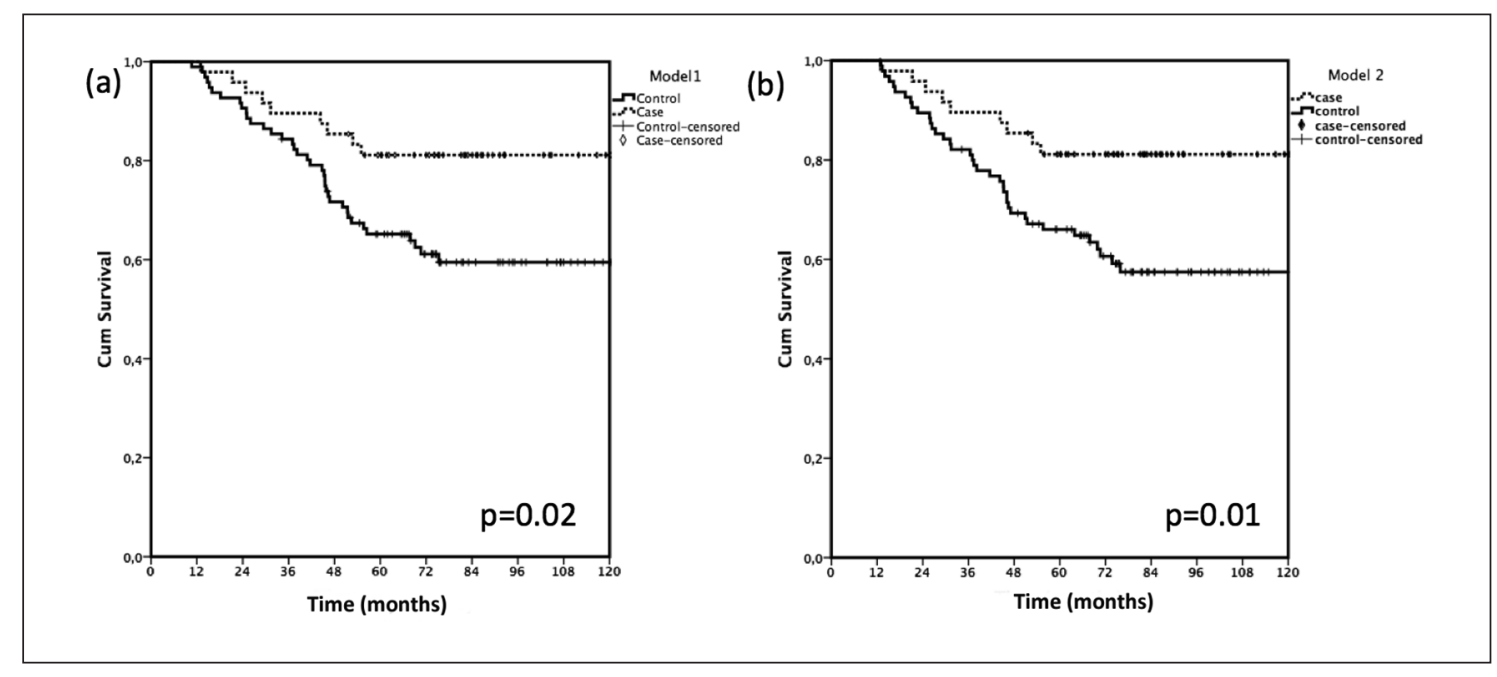

Fig. 1. Specific survival according to the groups. a Model 1. b Model 2.

Table 4. Comparison ${ }^{a}$ between groups according to survival

\begin{tabular}{|c|c|c|c|c|}
\hline & 36 months & 60 months & 96 months & $p^{\mathrm{b}}$ \\
\hline \multicolumn{5}{|c|}{ Overall survival } \\
\hline Case & 89.6 & 81.1 & 81.1 & \\
\hline Model 1 & 83.3 & 62.5 & 55.6 & 0.007 \\
\hline Model 2 & 80.2 & 62.5 & 54.4 & 0.005 \\
\hline \multicolumn{5}{|c|}{ Specific survival } \\
\hline Case & 89.6 & 81.1 & 81.1 & \\
\hline Model 1 & 84.4 & 65.2 & 59.2 & 0.02 \\
\hline Model 2 & 82.1 & 66.0 & 57.5 & 0.01 \\
\hline \multicolumn{5}{|c|}{ Disease-free survival } \\
\hline Case & 81.2 & 74.5 & 68.2 & \\
\hline Model 1 & 60.3 & 55.9 & 54.5 & 0.05 \\
\hline Model 2 & 61.0 & 57.7 & 54.7 & 0.07 \\
\hline \multicolumn{5}{|c|}{ Local recurrence-free survival } \\
\hline Case & 95.6 & 95.6 & 92.3 & \\
\hline Model 1 & 84.9 & 83.5 & 83.5 & 0.10 \\
\hline Model 2 & 86.7 & 85.2 & 85.2 & 0.16 \\
\hline
\end{tabular}

${ }^{\text {a }}$ Kaplan-Meier method. ${ }^{\text {b }}$ Log-rank.

vival $(p=0.007)$, specific survival $(p=0.02)$ and overall disease-free survival $(p=0.05)$ were lower in the model 1 group (Table 4; Fig. 1, 2).

\section{Control Model 2}

In this model, the patients were matched at a 1:2 ratio according to the TNM stage and the response to NCT. When the categorical variables were compared between the groups, the patients exhibited similar characteristics with respect to CS-TNM, T-TNM, N-TNM, histological type, histological grade, nuclear grade and response to NCT (Table 1, 4). However, they were different concern- ing the molecular subtype, as a higher proportion of luminal HER2-negative tumours ( $p=0.01$ ) was observed in the model 2 group (Table 1).

When the continuous variables were compared between the IBBR and model 2 groups (Table 2), the patients in the control group were older $(p=0.001)$, had larger tumours at diagnosis $(p=0.001)$ even after the matching attempt and presented a lower follow-up time $(p=0.05)$, which was also influenced by the lower overall and specific survival rates.

Evaluating the treatment (Table 3), there was a difference in the change of the proposed NCT regimen, which was borderline in the first model; it was significantly different in this model $(p=0.05)$ due to the greater proportion of patients who received the $4 \mathrm{AC} / 4 \mathrm{~T}$ scheme in the control group. Fewer patients underwent axillary-conserving surgery $(p=0.04)$, and the adjuvant treatment was similar.

The local recurrence was higher in this group (13.7\%; $\mathrm{OR}=2.4)$ but without a statistical significance $(p=0.26)$. Lung metastasis rate $(p=0.01)$ and cancer-specific death rate were higher in the model 2 group (Table 3$)$. Overall survival $(p=0.005)$, specific survival $(p=0.01)$ and overall disease-free survival $(p=0.07)$ were lower in the model 2 group, but local recurrence-free survival was higher in the IBBR group ( $p=0.16)$; however, this difference was not statistically significant (Table 4; Fig. 1, 2).

\section{Discussion}

Immediate and late reconstruction after mastectomy provides important psychosocial benefits to the women [33]. In the past, immediate reconstruction was based on 


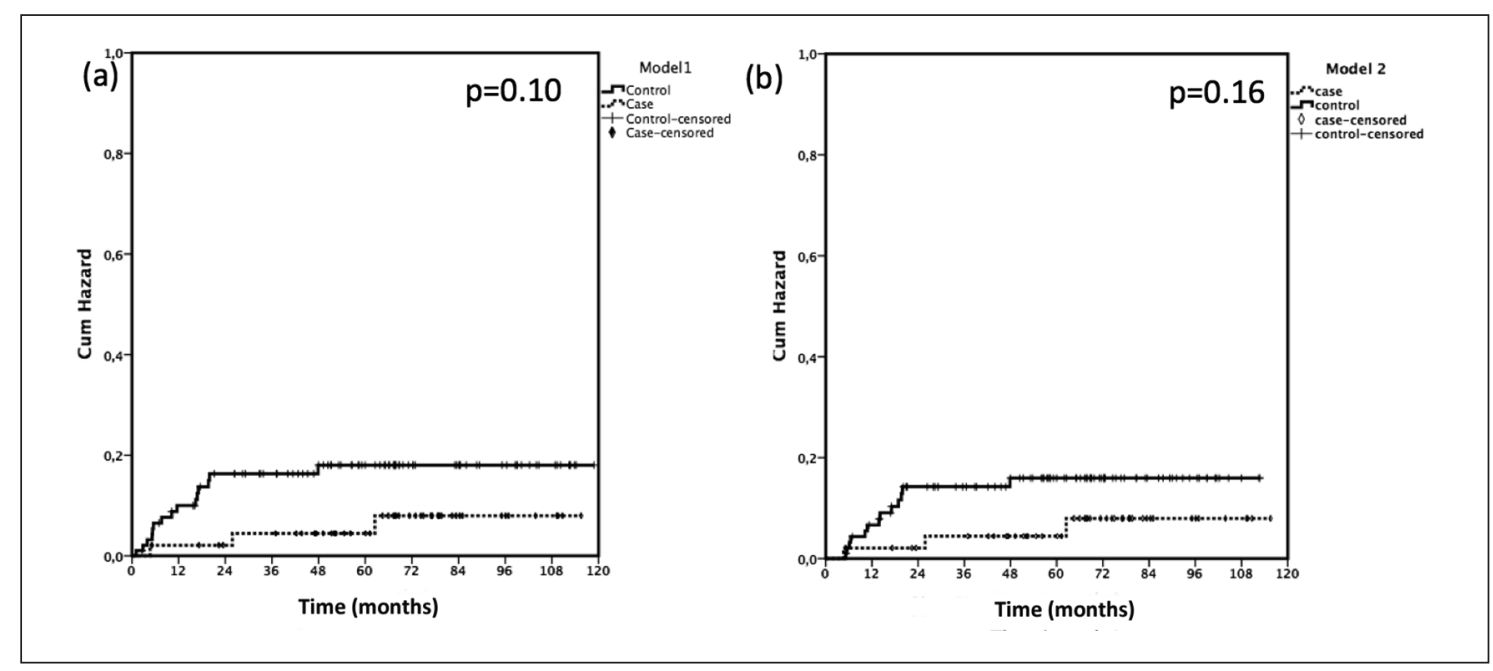

Fig. 2. Local recurrence according to the groups. a Model 1. b Model 2.

flaps, but now, the use of prosthesis is the most frequent procedure performed [34]. Although IBBR is a relatively new procedure in the conservative treatment of breast skin, the recurrence rates are low, and the degree of satisfaction is high [35]. Suggested indications include early stage and favourable biology. Despite earlier practices, NCT is no longer considered a contraindication $[35,36]$; however, the criteria for NCT are not clear [36], as the selection typically depends on a good response to therapy [37]. Patients who undergo NCT generally represent $13.7 \%[38,39]$ to $49 \%$ [40] of the series. In a study where they represented $100 \%$ [14], no control group was evaluated. In the present study, all patients underwent NCT, all had LABC, and 2 control groups were evaluated, which makes this study particularly interesting.

To evaluate the safety of IBBR through SSM or NSM, one of the alternatives has been the use of matched casecontrol studies that compare IBBR to CM. In matched case-control studies (IBBR vs. CM), different matching ratios were observed, including $1: 1.5$ to $1: 3$ [26, 41, 42], and different matching criteria were used, such as pathological stage, progesterone receptor, HER2, year of treatment [41], age, oestrogen receptor [26, 41], tumour size and axillary metastasis [26]. It was just possible to control variables before NCT using the proportion of 1:2. In the present study, which evaluated only patients with LABC, we opted to control the variables before NCT, and 2 matching models were evaluated: the first was based on pre-treatment criteria, while the second was based on CS and response to NCT. In the first model, after matching, the patients differed as to age and response to chemotherapy, and in the second model, the patients differed in terms of the molecular subtype. These 2 analyses were performed because patients with better response to NCT exhibited better survival, and we wanted to analyse the non-interference of this condition using the second model.

The safety and outcomes of IBBR are still poorly studied concerning patients with LABC who undergo NCT and adjuvant radiation therapy. Peled et al. [25] also evaluated LABC, and 107 patients (77\%) were submitted to NCT. The pCR was $12 \%$, and at 41 months of follow-up, $5 \%$ had local recurrence. Burdge et al. [14] exclusively evaluated LABC submitted to NCT $(n=60)$; they excluded T4-TNM tumours, and the average tumour size (3.8 $\mathrm{cm}$ ) and follow-up (median, 18 months) were lower, but they observed $11.7 \%$ locoregional and $0 \%$ local recurrence. Wengler et al. [27] evaluated 280 patients who exclusively underwent IBBR after NCT for early-stage tumours and LABC. The pCR rate was $17.5 \%, 71 \%$ of the patients received radiation therapy, and the local recurrence rate was $3.2 \%$, with a median follow-up of 45 months. However, $31.4 \%$ of patients had CS III $(88 / 280)$, and the mean tumour size and the follow-up were lower. In our IBBR group, the pCR was 27.1 months and the local recurrence rate was $6.2 \%$ at 74.7 months.

Ryu et al. [43] performed a similar study as the one presented here. They evaluated 31 patients submitted to IBBR, the matched proportion was 1:2.7, and the matching variables were age, CS before NCT, response to NCT and pathologic response after NCT. Progression during NCT was an exclusion criterion. $90 \%$ received the AC-T chemotherapy regimen. The locoregional recurrence rates were 9.7 and $7.1 \%$ for the immediate IBBR and CM groups, respectively. The maximum follow-up was 38.8 months. The overall survival, disease-free survival and local recurrence-free survival did not differ between the groups. 
Some studies describe locoregional recurrence [44], while others describe local recurrence. A meta-analysis of observational studies revealed no difference in the recurrence rate of CM (6.2\%) in relation to SSM (4.0\%) and reported a lower rate of distant recurrence in SSM. This finding should be carefully considered, since not all the prognostic variables were matched [5]. Another meta-analysis of studies which compared NSM with CM associated with SSM observed a $0.4 \%$ difference in the risk of local recurrence. However, the local recurrence rates were higher in the studies with a duration of more than 5 years of followup and were as high as $25.7 \%$ in a study with 135.6 months of follow-up [39]. In the present study, with 74.7 months of follow-up, no differences were observed between the groups in the local or locoregional recurrence rates.

A prospective series compared the effect of mastectomy (151 NSM and 61 CM) in patients undergoing NCT for T2-T3 and N0-N1 tumours. The exclusion criteria were disease progression and comorbidities. In this study, the whole group was compared without matching and differences were observed as to the clinical and pathological stage, $\mathrm{T}$ stage, $\mathrm{N}$ stage, the use of trastuzumab and radiation therapy, since the groups were different. Thus, a 1:1 matching (61:61) was performed, and similar characteristics were observed after matching. The local recurrence was $9.8 \%$ in the NSM group and $10.6 \%$ in the CM group, with a minimum median follow-up of 42.5 months. No difference was observed in disease-free survival between these matched groups ( $p=0.74)$ [28]. In our study, patients with disease progression were kept in the study, and matching was performed. Since some variables were controlled, and the matching was performed to reduce possible selection bias, IBBR was performed in patients with a better prognosis. Despite better pCR and specific survival in the IBBR group, we do not dare to associate these outcomes exclusively with the surgical treatment. Besides, local recurrence was not different between the groups. It is known that response to NCT is a significant predictor of disease-free survival, so we designed model 2. We believe that response to NCT must be considered in matched case-control studies.

One of the characteristics of the present study was the inclusion of T4 tumours in patients who underwent NCT, which has not been well studied. It should be noted that the T4 patients subjected to IBBR were selected from the overall group and, thus, they represented localized invasion, good response to therapy and possibility of IBBR using breast expanders [13]. Another study evaluating a retrospective series performed IBBR in 16 patients with inflammatory breast cancer, followed by radiotherapy. They observed no recurrence in a median follow-up of 2.3 years [45], but IBBR patients had more clinical complete response, a possible selection bias associated with retrospective studies.
Taxanes played an important role in neoadjuvant treatment [46] with an increase in the pCR rate (26.1 vs. $14.3 \%$ in the $\mathrm{AC}$ regimen) [47]; the same observation was made with neoadjuvant trastuzumab (78\% of pCR) [48]. A limitation of the present study is the non-systematic use of trastuzumab in all patients and its non-use in neoadjuvant treatment, but this occurred in both groups, which would standardize this possible study limitation.

Radiation therapy on the chest wall is indicated in patients with LABC. Radiation therapy increases the risk of infection 2.06 times and the risk of implant loss 4.05 times [49], and it increases the failure rate of reconstruction (18.6 vs. $3.1 \%$ ) and capsular contracture [50]. In the present study, $14.6 \%$ of patients with IBBR presented loss of prosthesis, and the main reasons for loss were skin necrosis and infection. 95.8\% of the patients received postoperative radiation therapy. The most common late complication was capsular contracture $(41.6 \%)$, a fact that can be attributed to the high number of patients submitted to radiotherapy and to the long follow-up.

The main limitation of this publication is a difference in the groups. As we wanted to examine local recurrence and survival, and as time has an impact on these factors, we chose a nested case-control model. It was difficult to control all the variables (matched), and 7 models were performed before analysis. We controlled the main variables, but the groups had few differences (Table 2). This illustrates how difficult it is to control all main variables in matched and nested case-control studies, particularly in studies with NCT, a fact that made us consider 2 control groups. We believe that the fact that IBBR patients had the best results was associated with a possible selection bias, as patients submitted to IBBR were younger, had a smaller tumour size and better pCR, although this was not significant in group 2 . These facts would contribute to a lower recurrence rate and a better survival and follow-up, due to matching of groups.

A better overall survival and cancer-related survival were found in the group of patients who underwent IBBR, a fact that can possibly be attributed to a selection bias when choosing patients with a better response for IBBR. This study seems to be the largest series that exclusively evaluated patients with IBBR after NCT for LABC, observing satisfactory results.

\section{Conclusion}

Although this is a small retrospective study, IBBR may be a safe and effective surgical procedure in selected patients with LABC. The level of evidence is 3B. IBBR is associated with higher associated surgical complications, but the reconstructive treatment did not change the local recurrence rate or local recurrence-free survival. 


\section{Statement of Ethics}

The Ethics and Research Committee approved this retrospective study under protocol numbers 135/2008 and 1308/2016.

\section{Funding Sources}

The main author received grants associated with this project by Fundação do Amparo a Pesquisa do Estado de São Paulo (FAPESP), grant number 2012/1962-0.

\section{Disclosure Statement}

The authors declare no conflicts of interest.

\section{References}

1 Newman LA. Management of patients with locally advanced breast cancer. Curr Oncol Rep. 2004 Jan;6(1):53-61.

2 Gieni M, Avram R, Dickson L, Farrokhyar F Lovrics P, Faidi S, et al. Local breast cancer recurrence after mastectomy and immediate breast reconstruction for invasive cancer: a meta-analysis. Breast. 2012 Jun;21(3):230-6.

3 Yang X, Zhu C, Gu Y. The prognosis of breast cancer patients after mastectomy and immediate breast reconstruction: a meta-analysis. PLoS One. 2015 May;10(5):e0125655.

4 Mota BS, Riera R, Ricci MD, Barrett J, de Castria TB, Atallah AN, et al. Nipple- and areolasparing mastectomy for the treatment of breast cancer. Cochrane Database Syst Rev. 2016 Nov; 11:CD008932.

5 Lanitis S, Tekkis PP, Sgourakis G, Dimopoulos N, Al Mufti R, Hadjiminas DJ. Comparison of skin-sparing mastectomy versus nonskin-sparing mastectomy for breast cancer: a meta-analysis of observational studies. Ann Surg. 2010 Apr;251(4):632-9.

6 Crisera CA, Chang EI, Da Lio AL, Festekjian $\mathrm{JH}$, Mehrara BJ. Immediate free flap reconstruction for advanced-stage breast cancer: is it safe? Plast Reconstr Surg. 2011 Jul;128(1): 32-41.

7 Nedumpara T, Jonker L, Williams MR. Impact of immediate breast reconstruction on breast cancer recurrence and survival. Breast. 2011 Oct;20(5):437-43

8 Kronowitz SI, Lam C, Terefe W, Hunt KK, Kuerer HM, Valero V, et al. A multidisciplinary protocol for planned skin-preserving delayed breast reconstruction for patients with locally advanced breast cancer requiring postmastectomy radiation therapy: 3-year follow-up. Plast Reconstr Surg. 2011 Jun; 127(6):2154-66.

9 Foster RD, Esserman LJ, Anthony JP, Hwang ES, Do H. Skin-sparing mastectomy and immediate breast reconstruction: a prospective cohort study for the treatment of advanced stages of breast carcinoma. Ann Surg Oncol. 2002 Jun;9(5):462-6.

10 Sultan MR, Smith ML, Estabrook A, Schnabe $\mathrm{F}$, Singh D. Immediate breast reconstruction in patients with locally advanced disease. Ann Plast Surg. 1997 Apr;38(4):345-9; discussion 350-1.
11 Downes KJ, Glatt BS, Kanchwala SK, Mick R, Fraker DL, Fox KR, et al. Skin-sparing mastectomy and immediate reconstruction is an acceptable treatment option for patients with high-risk breast carcinoma. Cancer. 2005 Mar;103(5):906-13.

12 Lim W, Ko BS, Kim HJ, Lee JW, Eom JS, Son $\mathrm{BH}$, et al. Oncological safety of skin sparing mastectomy followed by immediate reconstruction for locally advanced breast cancer. J Surg Oncol. 2010 Jul;102(1):39-42.

13 Zucca Matthes AG, Uemura G, Kerr L, Matthes AC, Michelli RA, Folgueira MA, et al. Feasibility of oncoplastic techniques in the surgical management of locally advanced breast cancer. Int J Surg. 2012;10(9):500-5

14 Burdge EC, Yuen J, Hardee M, Gadgil PV, Das C, Henry-Tillman R, et al. Nipple skin-sparing mastectomy is feasible for advanced disease. Ann Surg Oncol. 2013 Oct;20(10):3294302

15 Jones C, Lancaster R. Evolution of Operative Technique for Mastectomy. Surg Clin North Am. 2018 Aug;98(4):835-44.

16 Patani N, Mokbel K. Oncological and aesthetic considerations of skin-sparing mastectomy. Breast Cancer Res Treat. 2008 Oct;111(3): 391-403.

17 Carlson GW, Bostwick J 3rd, Styblo TM, Moore B, Bried JT, Murray DR, et al. Skinsparing mastectomy. Oncologic and reconstructive considerations. Ann Surg. 1997 May;225(5):570-8.

18 Nahabedian MY, Momen B. The impact of breast reconstruction on the oncologic efficacy of radiation therapy: a retrospective analysis. Ann Plast Surg. 2008 Mar;60(3): 244-50.

19 Tallet AV, Salem N, Moutardier V, Ananian P, Braud AC, Zalta R, et al. Radiotherapy and immediate two-stage breast reconstruction with a tissue expander and implant: complications and esthetic results. Int J Radiat Oncol Biol Phys. 2003 Sep;57(1):136-42.

20 Prabhu R, Godette K, Carlson G, Losken A, Gabram S, Fasola C, et al. The impact of skinsparing mastectomy with immediate reconstruction in patients with Stage III breast cancer treated with neoadjuvant chemotherapy and postmastectomy radiation. Int J Radiat Oncol Biol Phys. 2012 Mar;82(4):e587-93.

21 Ho AL, Tyldesley S, Macadam SA, Lennox PA. Skin-sparing mastectomy and immediate autologous breast reconstruction in locally advanced breast cancer patients: a UBC perspective. Ann Surg Oncol. 2012 Mar;19(3): 892-900.
22 Fersis N, Hoenig A, Relakis K, Pinis S, Wallwiener D. Skin-sparing mastectomy and immediate breast reconstruction: incidence of recurrence in patients with invasive breast cancer. Breast. 2004 Dec;13(6):488-93.

23 Medina-Franco H, Vasconez LO, Fix RJ, Heslin MJ, Beenken SW, Bland KI, et al. Factors associated with local recurrence after skinsparing mastectomy and immediate breast reconstruction for invasive breast cancer. Ann Surg. 2002 Jun;235(6):814-9.

24 Tanos G, Prousskaia E, Chow W, Angelaki A Cirwan C, Hamed H, et al. Locally Advanced Breast Cancer: Autologous Versus Implantbased Reconstruction. Plast Reconstr Surg Glob Open. 2016 Feb;4(2):e622.

25 Peled AW, Wang F, Foster RD, Alvarado M, Ewing CA, Sbitany H, et al. Expanding the Indications for Total Skin-Sparing Mastectomy: Is It Safe for Patients with Locally Advanced Disease? Ann Surg Oncol. 2016 Jan;23(1):8791.

26 Park SH, Han W, Yoo TK, Lee HB, Jin US Chang $\mathrm{H}$, et al. Oncologic Safety of Immediate Breast Reconstruction for Invasive Breast Cancer Patients: A Matched Case Control Study. J Breast Cancer. 2016 Mar;19(1):6875.

27 Wengler CA, Valente SA, Al-Hilli Z, Woody NM, Muntean JH, Abraham J, et al. Determinants of short and long term outcomes in patients undergoing immediate breast reconstruction following neoadjuvant chemotherapy. J Surg Oncol. 2017 Dec;116(7):797-802.

28 Agresti R, Sandri M, Gennaro M, Bianchi G, Maugeri I, Rampa M, et al. Evaluation of Local Oncologic Safety in Nipple-Areola Complex-sparing Mastectomy After Primary Chemotherapy: A Propensity Score-matched Study. Clin Breast Cancer. 2017 Jun;17(3): 219-31.

29 Goldhirsch A, Wood WC, Coates AS, Gelber RD, Thürlimann B, Senn HJ; Panel members. Strategies for subtypes-dealing with the diversity of breast cancer: highlights of the St. Gallen International Expert Consensus on the Primary Therapy of Early Breast Cancer 2011. Ann Oncol. 2011 Aug;22(8):1736-47.

30 Khokher S, Qureshi MU, Chaudhry NA. Comparison of WHO and RECIST criteria for evaluation of clinical response to chemotherapy in patients with advanced breast cancer. Asian Pac J Cancer Prev. 2012;13(7): 3213-8. 
31 Chen AM, Meric-Bernstam F, Hunt KK, Thames HD, Oswald MJ, Outlaw ED, et al. Breast conservation after neoadjuvant chemotherapy: the MD Anderson cancer center experience. J Clin Oncol. 2004 Jun;22(12): 2303-12.

32 Spear SL, Baker JL Jr. Classification of capsular contracture after prosthetic breast reconstruction. Plast Reconstr Surg. 1995 Oct 96(5):1119-23; discussion 1124.

33 Al-Ghazal SK, Sully L, Fallowfield L, Blamey RW. The psychological impact of immediate rather than delayed breast reconstruction. Eur J Surg Oncol. 2000 Feb;26(1):17-9.

34 Jagsi R, Jiang J, Momoh AO, Alderman A, Giordano SH, Buchholz TA, et al. Trends and variation in use of breast reconstruction in patients with breast cancer undergoing mastectomy in the United States. J Clin Oncol. 2014 Mar;32(9):919-26.

35 Galimberti V, Vicini E, Corso G, Morigi C, Fontana S, Sacchini V, et al. Nipple-sparing and skin-sparing mastectomy: review of aims, oncological safety and contraindications. Breast. 2017 Aug;34 Suppl 1:S82-4.

36 Santoro S, Loreti A, Cavaliere F, Costarelli L, La Pinta M, Manna E, et al. Neoadjuvant chemotherapy is not a contraindication for nipple sparing mastectomy. Breast. 2015 Oct; 24(5):661-6.

37 Boneti C, Yuen J, Santiago C, Diaz Z, Robertson Y, Korourian S, et al. Oncologic safety of nipple skin-sparing or total skin-sparing mastectomies with immediate reconstruction. Am Coll Surg. 2011 Apr;212(4):686-93; discussion 693-5.
38 Orzalesi L, Casella D, Santi C, Cecconi L, Murgo R, Rinaldi S, et al. Nipple sparing mastectomy: surgical and oncological outcomes from a national multicentric registry with 913 patients (1006 cases) over a six year period. Breast. 2016 Feb;25:75-81.

39 De La Cruz L, Moody AM, Tappy EE, Blankenship SA, Hecht EM. Overall Survival, Disease-Free Survival, Local Recurrence, and Nipple-Areolar Recurrence in the Setting of Nipple-Sparing Mastectomy: A Meta-Analysis and Systematic Review. Ann Surg Oncol. 2015 Oct;22(10):3241-9.

40 Warren Peled A, Foster RD, Stover AC, Itakura K, Ewing CA, Alvarado M, et al. Outcomes after total skin-sparing mastectomy and immediate reconstruction in 657 breasts. Ann Surg Oncol. 2012 Oct;19(11):3402-9.

41 Ryu JM, Paik HJ, Park S, Yi HW, Nam SJ, Kim SW, et al. Oncologic Outcomes after Immediate Breast Reconstruction Following Total Mastectomy in Patients with Breast Cancer: A Matched Case-Control Study. J Breast Cancer. 2017 Mar;20(1):74-81.

42 Adam H, Bygdeson M, de Boniface J. The oncological safety of nipple-sparing mastectomy - a Swedish matched cohort study. Eur J Surg Oncol. 2014 Oct;40(10):1209-15.

43 Ryu JM, Park S, Paik HJ, Nam SJ, Kim SW, Lee SK, et al. Oncologic Safety of Immediate Breast Reconstruction in Breast Cancer Patients Who Underwent Neoadjuvant Chemotherapy: Short-Term Outcomes of a Matched Case-Control Study. Clin Breast Cancer. 2017 Jun;17(3):204-10.

44 Piper M, Peled AW, Foster RD, Moore DH, Esserman LJ. Total skin-sparing mastectomy: a systematic review of oncologic outcomes and postoperative complications. Ann Plast Surg. 2013 Apr;70(4):435-7.
45 Simpson AB, McCray D, Wengler C, Crowe JP, Djohan R, Tendulkar R, et al. Immediate Reconstruction in Inflammatory Breast Cancer: Challenging Current Care. Ann Surg Oncol. 2016 Dec;23(S5 Suppl 5):642-8.

46 Rastogi P, Anderson SJ, Bear HD, Geyer CE, Kahlenberg MS, Robidoux A, et al. Preoperative chemotherapy: updates of National Surgical Adjuvant Breast and Bowel Project Protocols B-18 and B-27. J Clin Oncol. 2008 Feb; 26(5):778-85.

47 Bear HD, Anderson S, Smith RE, Geyer CE Jr, Mamounas EP, Fisher B, et al. Sequential preoperative or postoperative docetaxel added to preoperative doxorubicin plus cyclophosphamide for operable breast cancer: National Surgical Adjuvant Breast and Bowel Project Protocol B-27. J Clin Oncol. 2006 May;24(13): 2019-27.

48 Valachis A, Mauri D, Polyzos NP, Chlouverakis G, Mavroudis D, Georgoulias V. Trastuzumab combined to neoadjuvant chemotherapy in patients with HER2-positive breast cancer: a systematic review and meta-analysis. Breast. 2011 Dec;20(6):485-90.

49 Sbitany H, Wang F, Peled AW, Lentz R, Alvarado $\mathrm{M}$, Ewing $\mathrm{CA}$, et al. Immediate implant-based breast reconstruction following total skin-sparing mastectomy: defining the risk of preoperative and postoperative radiation therapy for surgical outcomes. Plast Reconstr Surg. 2014 Sep;134(3):396-404.

50 Lam TC, Hsieh F, Boyages J. The effects of postmastectomy adjuvant radiotherapy on immediate two-stage prosthetic breast reconstruction: a systematic review. Plast Reconstr Surg. 2013 Sep;132(3):511-8. 
